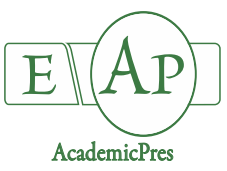

Enache I-M et al. (2021)

Notulae Botanicae Horti Agrobotanici Cluj-Napoca

Volume 49, Issue 2, Article number 12307

DOI: $10.15835 /$ nbha 49212307

Research Article

\title{
The optimization of a conventional extraction of bioactive compounds from Cornus mas by RSM and the determination of favourability factors by GIS technique
}

\author{
Iuliana-Maria ENACHE ${ }^{1}$, Gigi COMAN ${ }^{1}$, Sanda ROȘCA², \\ Camelia VIZIREANU ${ }^{1}$, Liliana MIHALCEA ${ }^{1 *}$
}
${ }^{1}$ Dunărea de Jos University of Galati, Faculty of Food Science and Engineering, 111 Domnească Street, 800201, Galați, Romania; iuliana.enache@ugal.ro; gigi.coman@ugal.ro; camelia.vizireanu@ugal.ro; liliana.gitin@ugal.ro(*corresponding author) ${ }^{2}$ Babeș Bolyai University, Faculty of Geography, Department of Physical and Technical Geography, 5-7 Clinicilor Street, 466664, Cluj-Napoca,Romania; sanda.rosca@ubbcluj.ro

\begin{abstract}
Rich in vitamins, polyphenols, carotenoids, carbohydrates, with a high antioxidant activity, cornelian cherry (Cornus mas) is one of the 65 species of Cornaceae family, fruits that are used in food industry, cosmetic industry or homeopathic medicine. The valuable bioactive compounds and the high economical potential of this tree makes suitable to be considered as a raw material to study the optimum extraction conditions in order to maximize the bioactive compounds' concentration. In this study, the main purpose was to investigate both the favourable and restrictive conditions for Cornus mas using the GIS technique. The Remote Sensing and Geographic Information Systems (GIS) technique indicated the favourability factors for Cornus mas trees in Romania country. The response surface methodology was employed to study the effect of temperature, time and solvent concentration on the flavonoids' (TFC) and polyphenols (TPC) concentrations and the antioxidant activity values. The maximum concentration of TPC (24.70 mg GAE/g raw material) and TFC $(1.36 \mathrm{mg} \mathrm{QE} / \mathrm{g}$ raw material) were obtained with $60 \%$ ethanol concentration at different temperature and time values. The cube model with centred faces for the Box-Behnken central composition revealed the highest value of the concentration of TAA ( $101.31 \mathrm{mg} \mathrm{TE} / \mathrm{g}$ raw material) at $100 \%$ ethanol concentration, $50^{\circ} \mathrm{C}$ extraction temperature and the maximum extraction time of $30 \mathrm{~min}$. The most relevant variable was the solvent concentration and the obtained results suggested that the central-face cube model ( $86 \%$ for TPC, $97 \%$ for TFC and $95 \%$ antioxidant activity) approximated the experimental data.
\end{abstract}

Keywords: bioactive compounds; conventional extraction; Cornus mas; GIS technique; response surface methodology

\section{Introduction}

The current climate changes such as the migration of some species towards higher altitudes, the drying of some forest species due to longer periods of drought, the increase of the sensitivity of forest species after snow damage, windfalls, drought, or identified soil erosion both globally and regionally have a major impact on the 
vegetation. Thus, there is a need to know the areas in which certain species will reduce their coverage, but also the favourable areas where there is the possibility of their expansion appears because of climate changes with direct implications in the forest management (Schiop et al., 2017; Seidl et al., 2017; Todea et al., 2020).

GIS technology allows the creation of a geospatial database by applying modern techniques of interpolation and spatial correlation. This includes the most relevant ecological indicators that positively and negatively influence the favourability of the species in Romania (Roșca et al., 2017). As such, by analysing climatic factors, such as the multiannual average precipitations, annual average temperature, topographic characteristics (elevation), soil characteristics (soil type and geology), several thematic maps and a raster database were generated. Furthermore, by applying geospatial modelling techniques, it is possible to include these elements in a quantitative GIS model of favourability classes for Cornus mas (C. mas). According to several studies, in Romania it can be found in the spontaneous flora (Cornescu and Cosmulescu, 2017). The high amount of biologically active compounds (BACs) such as vitamins, polyphenols, carotenoids, fatty acids, anthocyanins, tannins and carbohydrates found in the C. mas fruits makes them valuable for the food industry, cosmetic purposes and folk medicine. Many studies present the conventional extraction performed with different solvents such as: methanol, ethanol, acetone by the methods like: maceration, ultrasound-assisted or Soxhlet extraction (Dhanani et al., 2015; Altemimi et al., 2017; Dumitrascu et al., 2019).

C. mas fruits are used fresh or processed in food products, such as: jams, jelly, juices, liquor, marmalade, pestil (dried marmalade produced in Turkey), pekmez (syrup obtained in Turkey by fruit must), stewed fruit, syrups, tea infusions, wines (Güleryüz et al., 1998; Capanoglu et al., 2011; Sochor et al., 2014; NiziołEukaszewska et al., 2018). Some fresh fruits of $C$. mas genotypes from Turkey have indicated a vitamin $C$ content ranging from 36 to $122 \mathrm{mg} / 100 \mathrm{~mL}$ (Ercişli, 2004). Amongst the many benefits associated to humans health, cornelian cherry fruits are successfully used for: anaemia, cancer, diabetes, diarrhoea, fever, hyperlipidemia, gastrointestinal disorders, malaria, obesity, reducing intraocular pressure, urinary tract infections, as well as to have antioxidant and neuroprotective activity (Asgary et al., 2013; Szumny et al., 2015; Dinda et al., 2016). The cornelian cherry forest fruits were used as the whole plant by humans over the years due to geographical distribution.

The main purpose of this study was to achieve a collection of thematic maps for the national favourability classes for $C$. mas. Further the conventional extraction was performed in order to evaluate the optimum extraction parameters in regards to three different variables (temperature, time, and hydro alcoholic solution concentration) so as to maximize the total flavonoids' content (TFC), the total polyphenols' content (TPC) and the total antioxidant activity (TAA). Our research is important due to the high occurrence of $C$. mas at a national level as raw a material and also a good perspective for it to be use as food ingredients.

\section{Materials and Methods}

\section{GIS technique}

Considering the objectives of a study, GIS technology implementation is based on a spatial analysis considering of digital databases managed through the spatial analysis functions of geoinformation programs (Roșca et al., 2017).

This type of analysis techniques is used successfully in various studies to determine the most favourable agricultural crops (Islam et al., 2018; Matei et al., 2020), tree species (Beck et al., 2020) having the advantage of providing practical landscaping solutions at different scales of analysis taking into account the landscape and soil conditions but also depending on the market requirements ( $\mathrm{Zu}$ et al., 2014). Spatial analysis allows the adaptation of crops to global climate change that imposes requirements adapted to new climatic parameters using the Analytic Hierarchy Process (AHP) system (Acharya et al., 2021) the bivariate statistical analysis (BSA) or the analysis expert knowledge (Bhandari et al., 2013). But this aspect involves specialized technical 
knowledge, an interdisciplinary working group and the creation of a detailed database to understand the complexity of the involved ecological factors involved.

In our case, the first stage for the $C$. mas favourability determination was the acquisition of a database in a digital format (acquisition directly based on the spatial analysis sub models for the soil type and elevation, geological classes and the acquisition based on the implementation of the interpolation functions for the climatic factors).

The application of the actual spatial analysis based on the qualitative class determination through expert knowledge implies the granting of specific classes of favourability as well as the restrictiveness for the species studied within the entire territory of Romania (Table 1). It also implies as the final step - absolutely compulsory for the GIS models - the model validation stage (by directly comparing it to the reality from the field) in order to determine the predictability degree of predictability of the created model and the possible calibration of its parameters (Roșca et al., 2019).

Table 1. Favourability classes of the ecological factors used for the modelling of C. mas

\begin{tabular}{|c|c|c|c|c|}
\hline \multirow{2}{*}{ Factor } & \multicolumn{3}{|c|}{ Favorability for $C$. mas } & \multirow{2}{*}{ Sources } \\
\hline & Low & Medium & High & \\
\hline $\begin{array}{l}\text { Elevation } \\
(\mathrm{m})\end{array}$ & $<100$ & $>800$ & $100.1-800$ & $\begin{array}{l}\text { Copernicus Land Monitoring } \\
\text { Service - EU-DEM (EEA) }\end{array}$ \\
\hline $\begin{array}{l}\text { Air temperature } \\
\left({ }^{\circ} \mathrm{C}\right)\end{array}$ & $<-2$ & $-2 \ldots 10.5$ & $>10.5$ & $\begin{array}{c}\text { Implementation in GIS } \\
\text { environment of the regression } \\
\text { equation: } \\
\mathrm{Y}=0.395 \mathrm{X}+363.76 \text { where: } \\
\mathrm{Y} \text { - the average of the annual } \\
\text { precipitation, } \mathrm{mm} \\
\mathrm{X} \text { - the average of the annual } \\
\text { temperature, }{ }^{\circ} \mathrm{C}\end{array}$ \\
\hline $\begin{array}{l}\text { Average } \\
\text { precipitations } \\
(\mathrm{mm} / \text { year })\end{array}$ & $900 \mathrm{~mm} /$ year & $650-900 \mathrm{~mm} /$ year & $527-650 \mathrm{~mm} /$ year & $\begin{array}{c}\text { Implementation in GIS } \\
\text { environment of the regression } \\
\text { equation: } \\
\mathrm{Y}=0.435 \mathrm{X}+533.51 \text {, where: } \\
\mathrm{Y} \text { - the average of the annual } \\
\text { precipitation, } \mathrm{mm} \\
\mathrm{X} \text { - the relative altitude, } \mathrm{m}\end{array}$ \\
\hline Type of soil & $\begin{array}{l}\text { Cambiccherno } \\
\text { zem, } \\
\text { erodosoils, } \\
\text { alluvial soils }\end{array}$ & $\begin{array}{c}\text { Cernozioms } \\
\text { clayoiluvial, lacovisti, } \\
\text { podzoles, regosols, } \\
\text { vertisols }\end{array}$ & $\begin{array}{c}\text { Litosols, Rendzine, } \\
\text { Terra-rossa, } \\
\text { Cernozioms, } \\
\text { Preluvosols, Faeoziom, } \\
\text { Cernozioms }\end{array}$ & Soils Map of Romania, 1: 200000 \\
\hline Geology & $\begin{array}{l}\text { Breccias, salt } \\
\quad \text { diapir }\end{array}$ & $\begin{array}{l}\text { Gravels, flis deposits, } \\
\text { conglomerates, coluvial } \\
\text { deposits, alluvial } \\
\text { deposits, flish deposits }\end{array}$ & $\begin{array}{l}\text { Andesite, clays, leossoid } \\
\text { deposits, limestone, } \\
\text { marls, sandy deposits, } \\
\text { tuphogen rocks, current } \\
\text { alluvials, limestone }\end{array}$ & $\begin{array}{c}\text { Geological Map of Romania, } \\
1: 200000\end{array}$ \\
\hline
\end{tabular}

The validation of the results was performed through the comparison of the results obtained by applying the model developed in this study to frequency points reported in the European Atlas of Forest Species in Europe in the year of 2016.

\section{Chemicals and reagents}

Ethanol, aluminium chloride, potassium acetate, Folin-Ciocalteu reagent, sodium carbonate, gallic acid, methanol, (1,2-Diphenyl-1-picrylhydrazyl) DPPH, (6-Hydroxy-2,5,7,8-tetramethylchromane-2-carboxylic 
acid) Trolox were purchased Sigma-Aldrich (Steinheim, Germany). The chemicals used in this work were of analytical or HPLC grade.

\section{Sample processing}

The cornelian cherry fruits were collected from spontaneous flora from different village's hills of the Galati County, Romania, in September 2017. After being washed with distilled water, the fruits were blotted on paper towels and the stone of the fruits were removed. Afterwards, the fruits were freeze-dried (Christ Alpha 1-4 LD plus, Germany) at $-42{ }^{\circ} \mathrm{C}$ under a pressure of $0.10 \mathrm{mbar}$ for $72 \mathrm{~h}$. In order to obtain a compact powder, after lyophilization, the fruits were grinded under domestic conditions and stored at $4{ }^{\circ} \mathrm{C}$ for further experiments. In addition, 100 fruits and stones of cornelian cherry were measured and weighed in order to make a correlation between them and the characteristics of the fruit collection area used in this study.

\section{Conventional extraction method and the phytochemical characterization of the extracts}

The Design Expert software was used to analyse the influence of three different variables regarding the conventional extraction (CE) method (temperature 30-50 ${ }^{\circ} \mathrm{C}$, time $15-45 \mathrm{~min}$ and ethanol concentration 60$100 \%)$. In order to maximize the BACs content, the BOX-Behnken model with 15 experiments was used and for each experiment $1 \mathrm{~g}$ of lyophilized raw material and $10 \mathrm{ml}$ solvent were used. The total flavonoids content (TFC) was determined using a modified colorimetric method described by Turturică et al. (2016). The total polyphenols content (TPC) was determined using Folin-Ciocâlteu method, expressed as mg Gallic Acid Equivalent (GAE)/g raw material while the total antioxidant activity (TAA), expressed as mg Trolox/g raw material described as described by Vasile et al. (2020) and Oancea et al. (2017).

All the experiments were done using a water bath (Grant, OLS 200). All the measurements were replicated three times and the responses experimental values were expressed as the means.

\section{Response surface methodology}

The Response Surface Methodology (RSM) was applied to obtain the optimum conditions for the maximum extraction values of the TPC, the TFC and the TAA. The Box-Behnken design (BBD) was used to determine the optimum conditions for the CE method.

For the $\mathrm{CE}$ the three independent variables, namely extraction temperature $\left({ }^{\circ} \mathrm{C}, \mathrm{X}_{1}\right)$, extraction time $\left(\mathrm{min} ., \mathrm{X}_{2}\right)$ and solvent concentration $\left(\% \mathrm{EtOH}, \mathrm{X}_{3}\right)$ at three levels $(-1,0,+1)$ were investigated (Nipornram et al., 2018).

The coded and decoded values of the used independent variables used and their levels are shown in Table 1 and Table 2. The designs consisted of 15 randomized runs with three replicates at the central point and were analysed using the Design-Expert 6.0 Trial software (Stat-Ease, Minneapolis, Minnesota, USA) in terms of statistical analysis of variance, regression coefficients and regression equation. The experimental data for the three responses were fitted into a second-order polynomial model based on Eq. (1) in terms of the code factors, as follows:

$$
Y=\beta_{0}+\sum_{i=1}^{3} \beta_{i} X_{i}+\Sigma_{i=1}^{3} \beta_{i i} X_{i}^{2}+\sum \Sigma_{i=2}^{3} \beta_{i j} X_{i} X_{j}
$$

where $Y$ represents the response variable, $X_{\mathrm{i}}$ and $X_{\mathrm{j}}$ are the independent variables affecting the responses, and $\beta_{0}, \beta_{\mathrm{i}}, \beta_{\mathrm{ii}}$ and $\beta_{\mathrm{ij}}$ are the regression coefficients for the intercept, linear, quadratic and interaction terms (Zeković et al., 2014).

The optimum extraction conditions were determined considering the highest values for the total flavonoids, total polyphenols and the antioxidant activity values.

\section{Statistical analysis}

The Design-Expert 6.0 Trial (Stat-Ease, Minneapolis, Minnesota, USA) software was used for the Response Surface Methodology. The statistical analysis of the data was performed using ANOVA. 


\section{Results and Discussion}

\section{GIS technique}

To the best of our knowledge, in Romania only 38 areas were identified where the C. mas trees can grown, as described in Table 2 (Doniță et al., 2005).

Table 2. Romania's areas of cornelian cherry trees (Doniță et al., 2005)

\begin{tabular}{|l|l|l|l|l|l|l|l|l|l|}
\hline R3115 & R3129 & R4114 & R4126 & R4133 & R4137 & R4147 & R4153 & R4159 & R4164 \\
\hline R3122 & R3130 & R4120 & R4127 & R4134 & R4140 & R4149 & R4154 & R4160 & R4218 \\
\hline R3126 & R4111 & R4121 & R4129 & R4135 & R4141 & R4150 & R4156 & R4162 & \\
\hline R3128 & R4113 & R4124 & R4132 & R4136 & R4142 & R4151 & R4158 & R4163 & \\
\hline
\end{tabular}

1.R3115 South-East Carpathian bushes of Juniperus sabina

2.R3122 Ponto-Pannonic bushes of Prunus spinosa and Crataegus monogyna

3.R3126 South-East Carpathian bushes of Fraxinus ornus

4.R3128 Balkan bushes of Paliurus spina-christi

5.R3129 Balkan bushes of Jasminum fruticans

6.R3130 Ponto-Pannonic bushes of Cerasus fruticosa

7.R4111 South-East Carpathian forests of Fagus sylvatica and Abies alba with Cephalanthera damasonium

8.R4113 Balkan forests of Fagus sylvatica with Helleborus odororus

9.R4114 Mixed Balkan forests of Fagus sylvatica with Ruscus saculatus

10.R4120 Mixed Moldavian forests of Fagus sylavatica and Tilia tomentosa with Carex brevicollis

11.R4121 Balkan forests of Fagus sylvatica and Corylus colurna with Knautia drymeia

12.R4124 Dacian forests of Quercus petraea, Fagus sylvatica and Carpinus betulus with Lathyrus hallersteinii

13.R4126 Mixed Moldovan forests of Quercus petraea, Fagus sylvatica and Tilia tomentosa with Carex brevicollis

14.R4127 Mixed Dacian forests of Quercus petraea, Fagus sylvatica and Tilia tomentosa with Erythronium dens-canis

15.R4129 Dacian forests of Quercus petraea, Fagus sylvatica with Festuca drymeia

16.R4132 Pannonic-Balkan forests of Quercus petraea and Quercus cerris, Fagus sylvatica with Melittis melissophylum

17.R4133 Balkan forests of Quercus petraea with Helleborus odorus

18.R4134 Western-Pontic forests of Quercus petraea with Mercurialis ovata

19.R4135 West-Pontic mixed forest of Quercus petraea, Tilia tomentosa and Carpinus betulus with Carpesium cernuum

20.R4136 Mixed West-Pontic forests of Quercus petraea, Tilia tomentosa and Carpinus orientalis with Nectaroscordum siculum

21.R4137 Mixed West-Pontic forests of Quercus petraea and Tilia tomentosa with Galanthus plicatus

22.R4140 Daco-Balkan forests of Quercus petraea, Quercus cerris and Tilia tomentosa with Lychnis coronaria

23.R4141 Daco-Balkan forests of Quercus petraea and Castanea sativa with Genista tinctoria

24.R4142 Mixed Balkan forests of Quercus petraea and Corylus colurna with Paeonia dahurica

25.R4147 Mixed Danubian forests of Quercus robur and Tilia tomentosa with Scutellaria altissima

26.R4149Danubian-Balkan forests of Quercus cerris with Pulmonaria mollis

27.R4150 Danubian-Balkan forests of Quercus cerris with Festuca heterophylla

28.R4151 Mixed Balkan forests of Quercus cerris with Lithospermum purpurocaeruleum

29.R4153 Danubian-Balkan forests of Quercus cerris and Quercus frainetto with Crocus flavus 
30.R4154 Danubian-Balkan forests of Quercus frainetto with Festuca heterophylla

31.R4156 Danubian-Balkan forests of Quercus pedunculiflora, Quercus cerris, Quercus frainetto, Quercus pubescens with Acer tataricum

32.R4158 Mixed Danubian-West-Pontice forests of Quercus pedunculiflora and Tilia tomentosa with Viola jordanii

33.R4159 Danubian forests and rarities of Quercus pedunculiflora and Quercus robur with Tulipa bibersteiniana

34.R4160 Dacian forests-rarities of Quercus pubescens with Lithospermum purpurocaeruleum

35.R4162 Mixed West-Pontic forests of Quercus pubescens with Paeonia peregrina

36.R4163 Balkan forests-rarists of Quercus pubescens with Echinops bannaticus

37.R4164 Balkan forests of Juglans regia and Celtis australis with Scutellaria picheleri

38.R4218 Forests-rarists South-East carpathic of Pinus nigra spp. banatica with Genis taradiat

\section{Favourability of the environmental factors for $C$. mas trees in Romania}

Taking into account the preferences of the $C$. mas species, a database was created with the multiannual precipitations values from the meteorological stations in Romania. Based on the GIS spatial analysis technique and by using the equations between the precipitations level and the elevation, the grid of the multiannual average precipitations was obtained. This was converted by considering the favourability as well as the restrictiveness of the studied species.

Thus, the territories that benefit from values of an average multiannual precipitations lower than 650 $\mathrm{mm}$ /year were included in the classes of high favourability since the species has low requirements for water. The areas characterized by precipitation values between $650-900 \mathrm{~mm} / \mathrm{year}$ were included in the medium favourability class. Thus, the main part of the Transylvanian Plateau, the area of the Sub-Carpathian hills, but also that of the low mountains offer medium conditions to this species from the pluviometry point of view.

In the areas where the volume of precipitations surpasses $900 \mathrm{~mm} /$ year, the restrictive conditions were fulfilled for C. mas, therefore the high-mountainous area of the Romanian Carpathians was included in the low favourability classes (Figure 1).

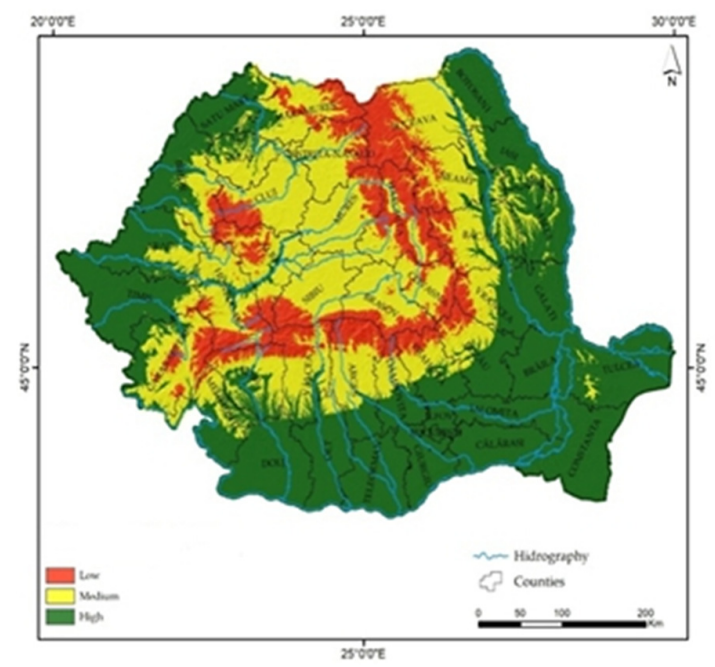

Figure 1. Favourability map for Cornus mas depending on the annual average precipitations

In Europe, according to the field observations taken by experts, the highest concentration of the species was identified in territories characterised by precipitation values between $500-800 \mathrm{~mm} /$ year and in the territories with air temperatures in the range of $8-12^{\circ} \mathrm{C}$ and with the solar radiation values during the springsummer season between 1500-1700 ( $\mathrm{kWh} \mathrm{m}^{2}$ ) (San-Miguel-Ayanz et al., 2016). 
By using the same procedural stages, the multiannual average temperature grid was obtained which was the basis in generating the map of favourability map for $C$. masin terms of the air temperature (Figure 2). Thus, it could be observed that that the largest part of the Romanian territory offers medium favourable conditions for $C$. mas. Only the areas of the Danube floodplain, the Bărăgan Plain and the seaside are characterised by temperatures higher than $10.5^{\circ} \mathrm{C}$. As such, these are characterised by the best development conditions of the species, whereas the limitative areas were identified in the high-mountainous areas, characterised by temperature values that can reach $2^{\circ} \mathrm{C}$.

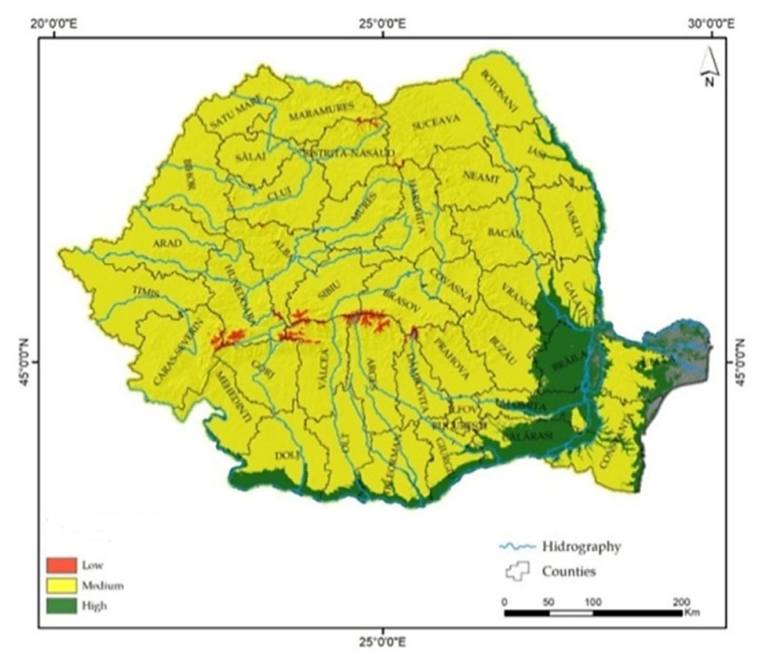

Figure 2. Favourability for Cornus mas depending on the air temperature

Considering the influence of the elevation on the precipitations' volume, on the air temperature and, implicitly, on the pedological characteristics, and by using the information provided by the scientific literature on the ecological requirements of the analysed species, the Romanian territory was classified based on three favourability classes. The areas with an elevation lower than $100 \mathrm{~m}$ offer limitative conditions for the cultivation of $C$. mas, whereas the areas within the elevation 100-800 m offer good development conditions. Thus, the high areas characterised by a higher elevation than $800 \mathrm{~m}$ may become restrictive to the development and the achievement of an increased consistency of the species.

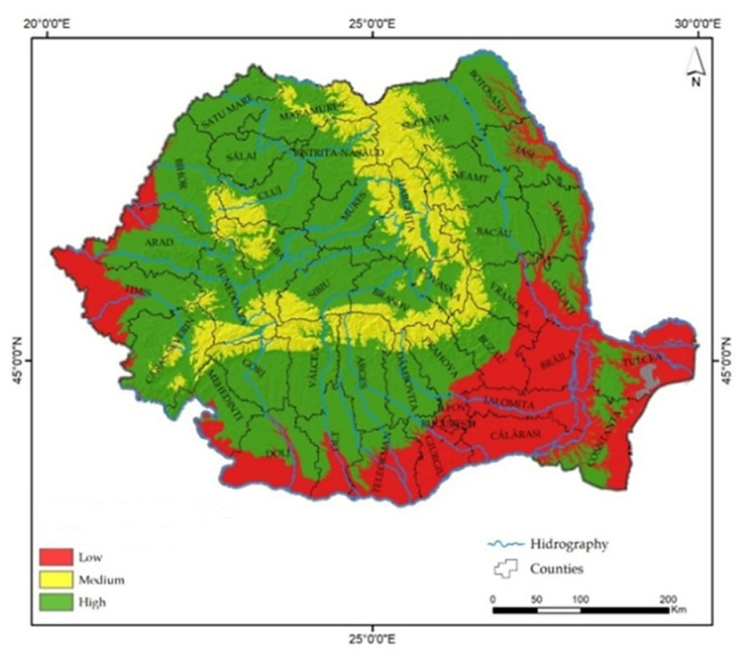

Figure 3. Favourability for C. mas depending on the elevation 
The analysis of the forest habitats' types from Romania, where C. mas grows, allowed a classification based on favourability classes correlated to the soil types (Figure 3, Table 1). It can be notice that a considerable part of the Romanian territory $\left(143010 \mathrm{~km}^{2}\right.$ representing $\left.59.85 \%\right)$ offers favourable conditions for the development of the species through the presence of specific soil types: Lithosols, Rendzinas, Terra-rossa, Chernozem, Preluvosoil, Phaeozem. The restrictive conditions are fulfilled on an approximately $25.16 \%$ of the national territory where types of soil such as Cambic Chernozem, Erodosoils, alluvial soils are present, whereas the other $14.9 \%$ of the territory offers medium conditions for the analysed species (Figure 4).

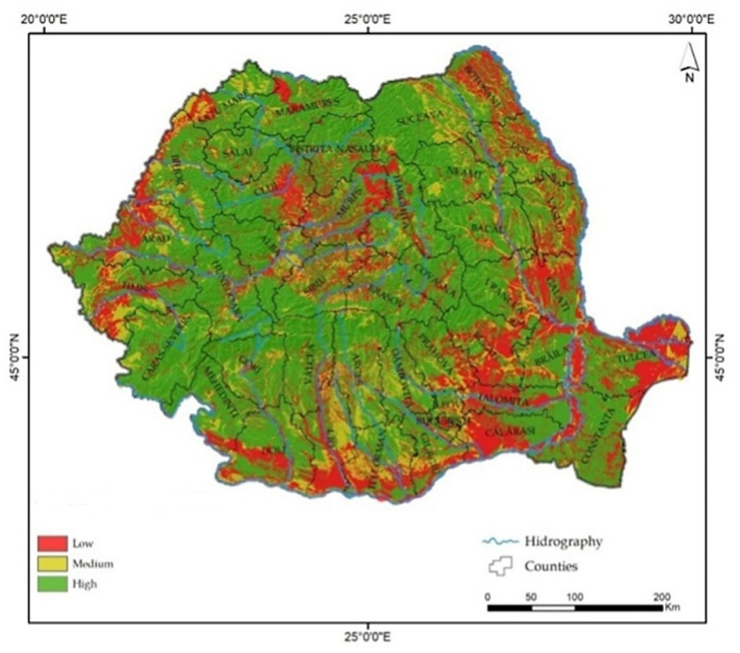

Figure 4. Favourability for Cornus mas depending on the type of soil

Another factor taken into consideration was the geological deposit. Each geological class mapped on the Geological Map of Romania 1:200000 was classified by the favourability classes for $C$. mas considering the geology of forest habitats at the level of which this species was identified (Table 1). Therefore, a large part of the Romanian territory ( $58.9 \%$ of its surface) offers favourable conditions for $C$. mas. Only $4.2 \%$ imposes limits within the territories with salt deposits whereas the other territories offer medium development conditions for the studied species (Figure 5).

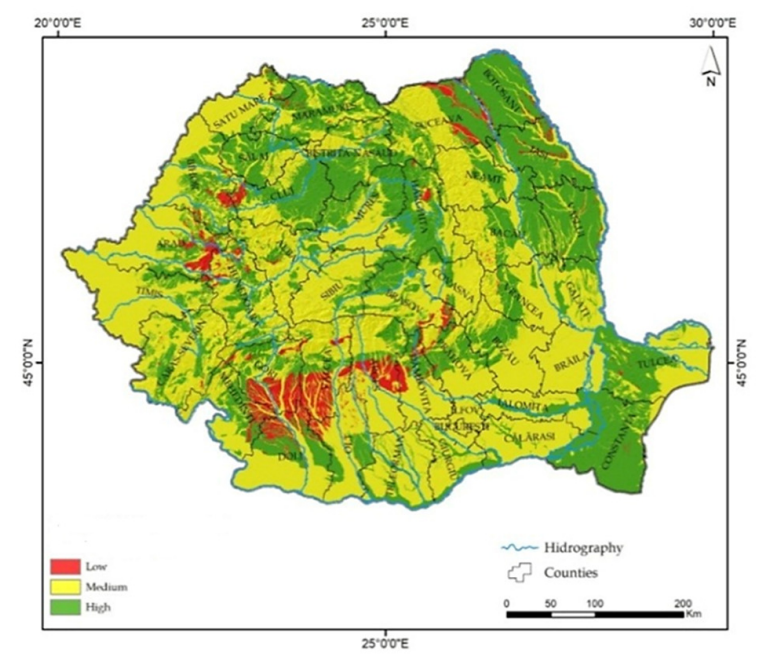

Figure 5. Favourability for C. mas depending on geology 
At a national level, the GIS analysis has highlighted the medium and the high favourability classes for $C$. mas which represented $75 \%$ of the studied territory, due to climatic, soil and geological conditions (Figure 6).

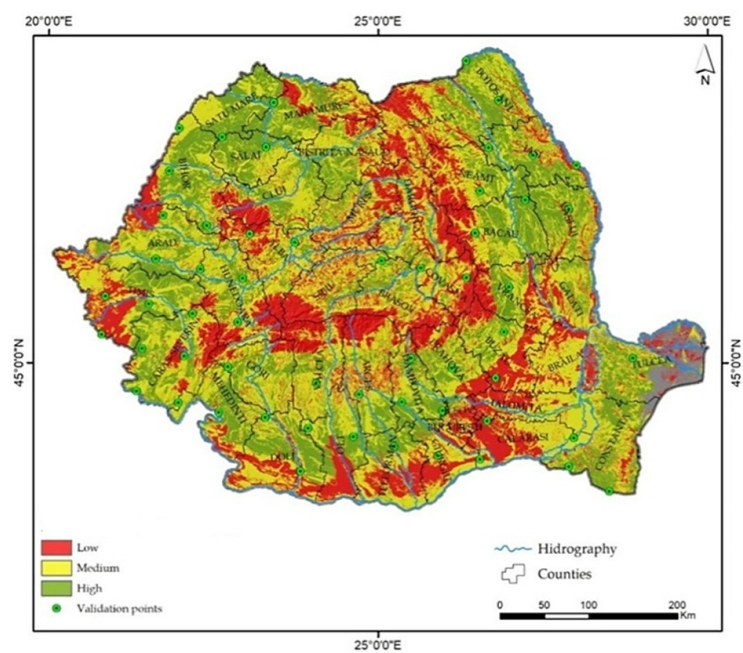

Figure 6. Favourability for C. mas depending on all the parameters (climatic, soil and geological conditions)

The largest areas that can support the development of the species and the obtainment of abundant fructification are located in several counties, such as: Bihor, Constanța and Bacău, whereas the most restrictive areas are located in the following counties: Suceava, Timiș, Harghita etc. (Table 3).

The validation of the model was made by using the reclassified result obtained from the implementation of a spatial analysis (favourability or restrictiveness for $C$. mas and a vector database of a polygon type. This was obtained from a direct acquisition representing geographical locations of the areas where the species exceeds $25 \%$ of the consistency of the habitats in which it develops, according to the Atlas of Species in Europe. Therefore, a validation rate of $83.5 \%$ of the results was identified, which reflects the high level of sensitivity of the applied model (28 safe locations in the field where the $C$. mas species was identified, located in areas are included in the high favourability class, whereas 19 are present in the medium favourability class).

\section{Response Surface Methodology for the CE method of the BACs from cornelian cherry fruits}

The experimental values were fitted to a second-order polynomial model (Eq.1) and the multiple regression coefficients were generated for all the responses using a statistical approach to determine the influence of the extraction parameters on the BACs from C. mas fruits.

The highest values for the BACs were obtained at $40^{\circ} \mathrm{C}, 15 \mathrm{~min}$ and $60 \%$ hydro alcoholic solution, a Gallic Acid Equivalent GAE, $24.70 \pm 0.92 \mathrm{mg} / \mathrm{g}$ raw material, a Quercetin Equivalent QE, $1.36 \pm 0.00 \mathrm{mg} / \mathrm{g}$ raw material was obtained at $30{ }^{\circ} \mathrm{C}, 30 \mathrm{~min}$ and $60 \%$ hydro alcoholic solution, whereas the total antioxidant activity, of $101.31 \pm 3.90 \mathrm{mg}$ Trolox $/ \mathrm{g}$ raw material, was detected at $50^{\circ} \mathrm{C}, 30 \mathrm{~min}$ and $100 \%$ etanol $(\mathrm{EtOH})$. 
Enache I-M et al. (2021). Not Bot Horti Agrobo 49(2):12307

Table 3. Classification based on the favourability classes for C. mas in the Romanian counties

\begin{tabular}{|c|c|c|c|}
\hline \multirow{2}{*}{ County } & \multicolumn{3}{|c|}{ Favourability Classes Area $\left(\mathrm{km}^{2}\right)$} \\
\hline & Low & Medium & High \\
\hline Alba & 2120.4 & 3531.5 & 597.2 \\
\hline Arad & 1226.6 & 4122.5 & 2399.8 \\
\hline Arges & 2103.3 & 3542.6 & 1184.8 \\
\hline Bacãu & 1165.9 & 2715.0 & 2746.7 \\
\hline Bihor & 1007.9 & 3338.4 & 3202.5 \\
\hline Bistrita Nãsãud & 838.6 & 2795.8 & 1724.7 \\
\hline Botosani & 380.3 & 2178.1 & 2385.2 \\
\hline Brãila & 1527.7 & 3103.8 & 0.9 \\
\hline Brasov & 1748.3 & 2647.3 & 972.4 \\
\hline Bucuresti & 137.8 & 95.7 & 2.3 \\
\hline Buzãu & 2530.1 & 2634.0 & 943.9 \\
\hline Cãlãrasi & 2283.1 & 2675.5 & 131.6 \\
\hline Caras_Severin & 1594.4 & 4230.9 & 2697.9 \\
\hline Cluj & 1344.5 & 3501.6 & 1833.0 \\
\hline Constanta & 674.4 & 3093.9 & 3026.6 \\
\hline Covasna & 1515.7 & 1898.5 & 297.6 \\
\hline Dâmbovita & 388.1 & 1880.4 & 1789.3 \\
\hline Dolj & 1927.4 & 3225.0 & 2261.5 \\
\hline Galati & 1029.8 & 2328.6 & 1052.5 \\
\hline Giurgiu & 1180.2 & 1864.9 & 499.9 \\
\hline Gorj & 903.0 & 3091.2 & 1511.0 \\
\hline Harghita & 2719.1 & 3278.0 & 646.6 \\
\hline Hunedoara & 1849.0 & 3808.5 & 1412.9 \\
\hline Ialomita & 1392.8 & 2811.5 & 256.0 \\
\hline Iasi & 849.7 & 2178.5 & 2435.1 \\
\hline Ilfov & 776.7 & 629.0 & 166.0 \\
\hline Maramures & 1243.1 & 2482.6 & 2580.7 \\
\hline Mehedinti & 678.8 & 2374.7 & 1894.4 \\
\hline Mures & 2467.5 & 3285.7 & 965.6 \\
\hline Neamt & 1585.0 & 2751.1 & 1569.8 \\
\hline Olt & 1573.3 & 2189.1 & 1744.8 \\
\hline Prahova & 1440.1 & 1970.8 & 1309.2 \\
\hline Sãlaj & 61.2 & 1617.2 & 2190.4 \\
\hline Satu_Mare & 50.2 & 1850.8 & 2504.3 \\
\hline Sibiu & 2254.3 & 2747.4 & 434.6 \\
\hline Suceava & 3099.0 & 4079.6 & 1377.1 \\
\hline Teleorman & 1958.1 & 2666.5 & 1165.5 \\
\hline Timis & 2744.4 & 3815.8 & 2138.2 \\
\hline Tulcea & 1128.8 & 2332.3 & 2080.1 \\
\hline Vâlcea & 1941.4 & 3087.8 & 827.0 \\
\hline Vaslui & 591.4 & 2085.6 & 2647.5 \\
\hline Vrancea & 1601.9 & 1883.3 & 1375.9 \\
\hline Total area & 59633.2 & 112421.2 & 66335.8 \\
\hline & $25,0 \%$ & $47,2 \%$ & $27,8 \%$ \\
\hline
\end{tabular}


Table 4. The experimental data for the TPC, TFC and TAA by CE method using the Box-Behnken model

\begin{tabular}{|c|c|c|c|c|c|c|c|c|c|}
\hline \multirow{3}{*}{ Run } & \multicolumn{6}{|c|}{ Extraction conditions } & \multicolumn{3}{|c|}{$\begin{array}{c}\text { Response variables, as mean } \pm \text { S.E. } \\
\text { (in } \mathrm{mg} / \mathrm{g} \text { raw material) }\end{array}$} \\
\hline & \multicolumn{3}{|c|}{$\begin{array}{c}\text { Coded } \\
\text { variables }\end{array}$} & \multicolumn{3}{|c|}{ Decoded variables } & \multirow{2}{*}{ GAE } & \multirow{2}{*}{ QE } & \multirow{2}{*}{ Trolox } \\
\hline & $\mathrm{X}_{1}$ & $\mathrm{X}_{2}$ & $\mathrm{X}_{3}$ & $\begin{array}{l}\text { Tempe- } \\
\text { rature, }{ }^{\circ} \mathrm{C}\end{array}$ & $\begin{array}{l}\text { Time, } \\
\text { min. }\end{array}$ & $\begin{array}{c}\mathrm{EtOH}, \\
\%\end{array}$ & & & \\
\hline 1 & -1 & -1 & 0 & 30 & 15 & 80 & $17.65 \pm 0.17$ & $1.04 \pm 0.07$ & $10.03 \pm 1.90$ \\
\hline 2 & 1 & -1 & 0 & 50 & 15 & 80 & $16.08 \pm 0.25$ & $1.09 \pm 0.05$ & $23.53 \pm 3.31$ \\
\hline 3 & -1 & 1 & 0 & 30 & 45 & 80 & $14.66 \pm 0.64$ & $0.93 \pm 0.08$ & $21.19 \pm 0.02$ \\
\hline 4 & 1 & 1 & 0 & 50 & 45 & 80 & $10.61 \pm 0.49$ & $1.10 \pm 0.05$ & $56.03 \pm 3.70$ \\
\hline 5 & -1 & 0 & -1 & 30 & 30 & 60 & $23.31 \pm 0.31$ & $1.36 \pm 0.00$ & $13.62 \pm 3.39$ \\
\hline 6 & 1 & 0 & -1 & 50 & 30 & 60 & $22.51 \pm 0.44$ & $1.18 \pm 0.01$ & $8.38 \pm 0.88$ \\
\hline 7 & -1 & 0 & 1 & 30 & 30 & 100 & $0.89 \pm 0.06$ & $0.23 \pm 0.02$ & $98.48 \pm 1.71$ \\
\hline 8 & 1 & 0 & 1 & 50 & 30 & 100 & $1.52 \pm 0.16$ & $0.08 \pm 0.00$ & $101.31 \pm 3.90$ \\
\hline 9 & 0 & -1 & -1 & 40 & 15 & 60 & $24.70 \pm 0.92$ & $1.30 \pm 0.01$ & $9.17 \pm 2.86$ \\
\hline 10 & 0 & 1 & -1 & 40 & 45 & 60 & $19.13 \pm 1.13$ & $1.17 \pm 0.00$ & $10.97 \pm 1.72$ \\
\hline 11 & 0 & -1 & 1 & 40 & 15 & 100 & $2.12 \pm 0.08$ & $0.19 \pm 0.01$ & $91.93 \pm 1.27$ \\
\hline 12 & 0 & 1 & 1 & 40 & 45 & 100 & $1.66 \pm 0.08$ & $0.32 \pm 0.03$ & $88.77 \pm 1.15$ \\
\hline 13 & 0 & 0 & 0 & 40 & 30 & 80 & $8.21 \pm 0.13$ & $0.89 \pm 0.00$ & $48.35 \pm 4.83$ \\
\hline 14 & 0 & 0 & 0 & 40 & 30 & 80 & $8.03 \pm 0.08$ & $0.97 \pm 0.07$ & $56.18 \pm 0.92$ \\
\hline 15 & 0 & 0 & 0 & 40 & 30 & 80 & $13.23 \pm 0.17$ & $1.07 \pm 0.06$ & $37.22 \pm 4.31$ \\
\hline
\end{tabular}

The regression coefficients of the fitted second-order polynomial model for the BACs expressed as GAE, $\mathrm{QE}$ and Trolox Equivalents are presented in Table 5.

Table 5. The estimated coefficients of the fitted second-order polynomial model for the analysed BACs

\begin{tabular}{|l|c|c|c|}
\hline \multirow{2}{*}{ Regression Coefficients } & \multicolumn{3}{c|}{ Response, $\mathrm{mg} / \mathrm{g}$ raw material } \\
\cline { 2 - 4 } & GAE & QE & Trolox \\
\hline$\beta_{0}$ & 14.278 & -0.029 & -8.887 \\
\hline A. Temperature, ${ }^{\circ} \mathrm{C}$ & -2.123 & -0.021 & 4.4303 \\
\hline B. Time, min. & -0.933 & 0.037 & 2.5691 \\
\hline $\mathrm{C}$. EtOH concentration, \% & -0.579 & 0.077 & -4.3093 \\
\hline $\mathrm{AB}$ & -0.004 & 0.0002 & 0.0355 \\
\hline $\mathrm{AC}$ & 0.002 & 0.00004 & 0.010 \\
\hline $\mathrm{BC}$ & 0.004 & 0.0002 & -0.0041 \\
\hline $\mathrm{A}^{2}$ & 0.025 & 0.00013 & -0.0716 \\
\hline $\mathrm{B}^{2}$ & 0.010 & 0.00020 & -0.0551 \\
\hline $\mathrm{C}^{2}$ & 0.0007 & 0.00069 & 0.0384 \\
\hline
\end{tabular}

The analysis of variances (ANOVA) of the fitted second-order polynomial model for the TPC, TFC and TAA responses is summarized in Table 6.

The high values of coefficients of multiple determination for all BACs $\left(\mathrm{R}^{2}{ }_{\mathrm{TPC}}=0.86\right.$, $\mathrm{R}_{\mathrm{TFC}}^{2}=0.97$ and $\mathrm{R}_{\mathrm{TAA}}^{2}=0.95$, respectively) through the model equations provided a good representation of the experimental values. For all three responses (the TPC, the TFC and the TAA), the mathematical models were statistically acceptable due to a significant regression for the model, $\mathrm{p}<0.05$ (Table 6). For this model, the lackof-fit values confirmed the adequacy of the experimental data fitting with insignificant $p$-values were $(p>0.05)$. 
Table 6. Analysis of variances (ANOVA) of the fitted second-order polynomial model for TPC, TFC and TAA

\begin{tabular}{|c|c|c|c|c|c|}
\hline & Sum of squares & DF & Mean square & F-Value & $\mathrm{p}$-Value \\
\hline \multicolumn{6}{|c|}{$\mathrm{TPC}\left(\mathrm{GAE}^{\mathrm{a}}, \mathrm{mg} / \mathrm{g}\right)$} \\
\hline Model & 952.88 & 9 & 105.88 & 22.71 & $0.0015^{s}$ \\
\hline Residual & 23.31 & 5 & 4.66 & & \\
\hline Lack of fit & 5.87 & 3 & 1.96 & 0.2243 & $0.8737^{\mathrm{ns}}$ \\
\hline Pure error & 17.44 & 2 & 8.72 & & \\
\hline Total & 976.19 & 14 & & & \\
\hline \multicolumn{6}{|c|}{ TFC $\left(\mathrm{QE}^{\mathrm{b}}, \mathrm{mg} / \mathrm{g}\right)$} \\
\hline Model & 2.52 & 9 & 0.2795 & 21.26 & $0.0018^{\mathrm{s}}$ \\
\hline Residual & 0.0657 & 5 & 0.0131 & & \\
\hline Lack of fit & 0.0490 & 3 & 0.0163 & 1.95 & $0.3568^{\mathrm{ns}}$ \\
\hline Pure error & 0.0168 & 2 & 0.0084 & & \\
\hline Total & 2.58 & 14 & & & \\
\hline \multicolumn{6}{|c|}{ Total Antioxidant Activity TAA (mg Trolox/gc) } \\
\hline Model & 16692.25 & 9 & 1854.69 & 11.67 & $0.0073^{\mathrm{s}}$ \\
\hline Residual & 794.48 & 5 & 158.90 & & \\
\hline Lack of fit & 613.01 & 3 & 204.34 & 2.25 & $0.3222^{\mathrm{ns}}$ \\
\hline Pure error & 181.47 & 2 & 90.73 & & \\
\hline Total & 17486.72 & 14 & & & \\
\hline
\end{tabular}

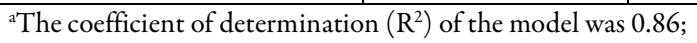

${ }^{b}$ The coefficient of determination $\left(\mathrm{R}^{2}\right)$ of the model was 0.97 ;

'The coefficient of determination $\left(\mathrm{R}^{2}\right)$ of the model was 0.95 ;

s - significant;

ns - not significant.

The GAE response was not significantly influenced by the combined action of the time-temperature parameters. A decrease in the TPC was observed at $40{ }^{\circ} \mathrm{C}$ and 30 minutes. The use of the temperature of $30^{\circ} \mathrm{C}$ and an extraction time in the range between 15 and 45 min allowed a satisfactory concentration in the TPC (Figure 7A). The influence of the combined action of the $\mathrm{EtOH}$ - extraction temperature parameters revealed a considerable increase of the TPC at the concentration of $60 \% \mathrm{EtOH}$ throughout the temperature range between 30 to $50^{\circ} \mathrm{C}$ (Figure $7 \mathrm{~B}$ ). Using an optimum of EOH concentration of $60 \%$, the optimum of extraction time for the temperature range between $30-50{ }^{\circ} \mathrm{C}$, was maximum 15 minutes. Any increase in time over 15 minutes led to a decrease of the TPC (Figure 7C).

The QE response was not significantly influenced by the combined action of the time-temperature parameters. A decrease of the TFC was observed at $40{ }^{\circ} \mathrm{C}$ and 30 minutes of extraction. The use of the temperature of $30^{\circ} \mathrm{C}$ and an extraction time between $15-30$ min will allow a satisfactory concentration in QE (Figure 8A). The influence of the combined action of the $\mathrm{EtOH}$ - temperature parameters revealed a considerable the TFC increase at an $\mathrm{EtOH}$ concentration in the range $60-80 \%$ throughout the temperature range between $30-50^{\circ} \mathrm{C}$ (Figure $8 \mathrm{~B}$ ). Using an $\mathrm{EtOH}$ concentration between $60-70 \%$ in the temperature range between $30-50{ }^{\circ} \mathrm{C}$, the optimum extraction time was 15 minutes. Any increase in time over 15 minutes leads to a decrease in the concentration of the TFC content (Figure 8C).

The TAA response was influenced by the combined action of the time-temperature parameters. The use of a temperature found in the $40{ }^{\circ} \mathrm{C}$ to $50{ }^{\circ} \mathrm{C}$ range and a time interval of between $30-45 \mathrm{~min}$., will allow a satisfactory TAA to be obtained. The use of a higher temperature revealed a better resistance of the phenolic compounds expressed as Trolox Equivalents (Figure 9A). The influence of the combined action of the EtOHtemperature concentration parameters revealed a considerable increase of the TAA at a 95-100\% co-solvent $\mathrm{EtOH}$ concentration throughout the temperature range between $30^{\circ} \mathrm{C}$ to $50^{\circ} \mathrm{C}$ (Figure 9B). 
Enache I-M et al. (2021). Not Bot Horti Agrobo 49(2):12307
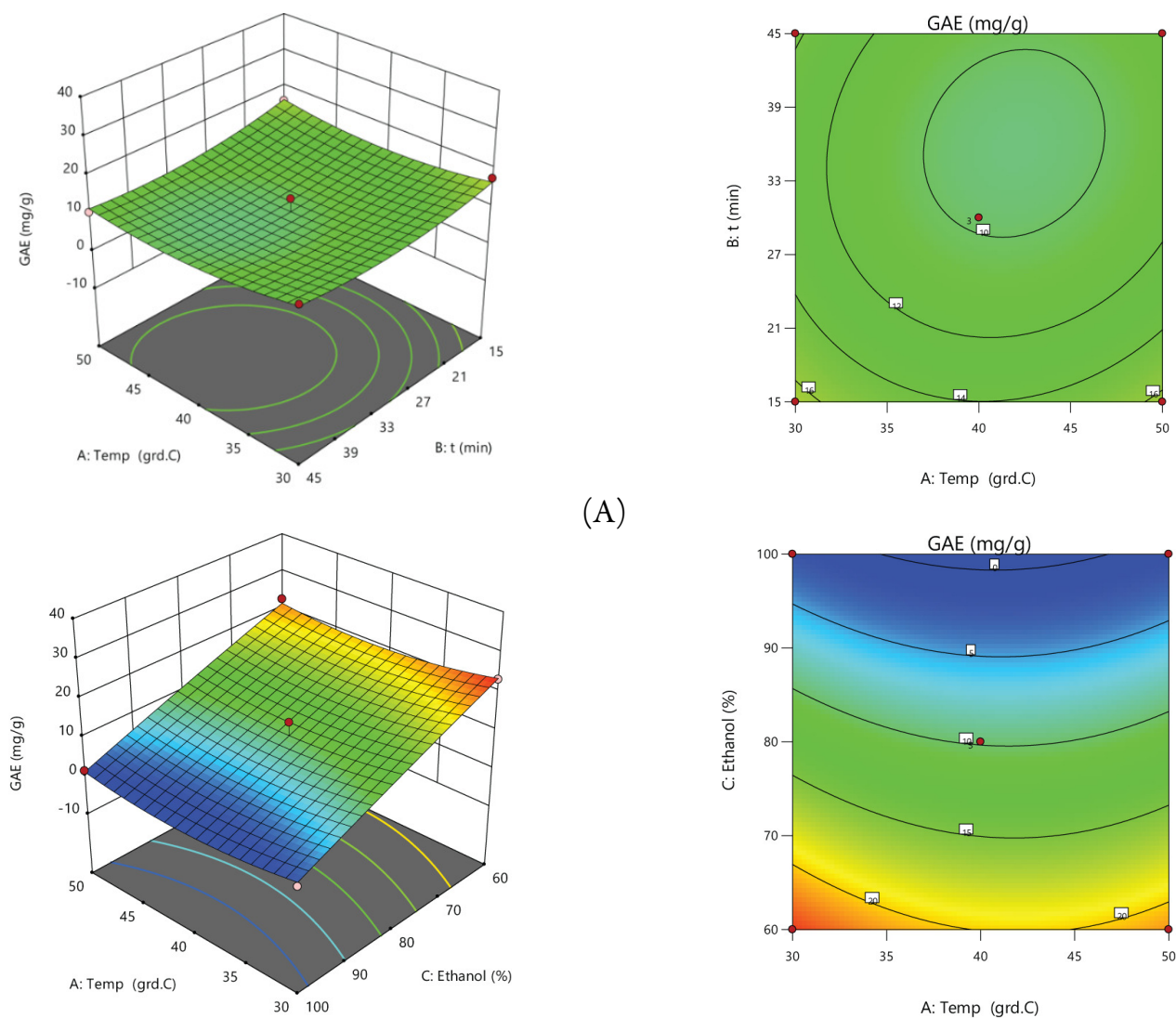

(A)
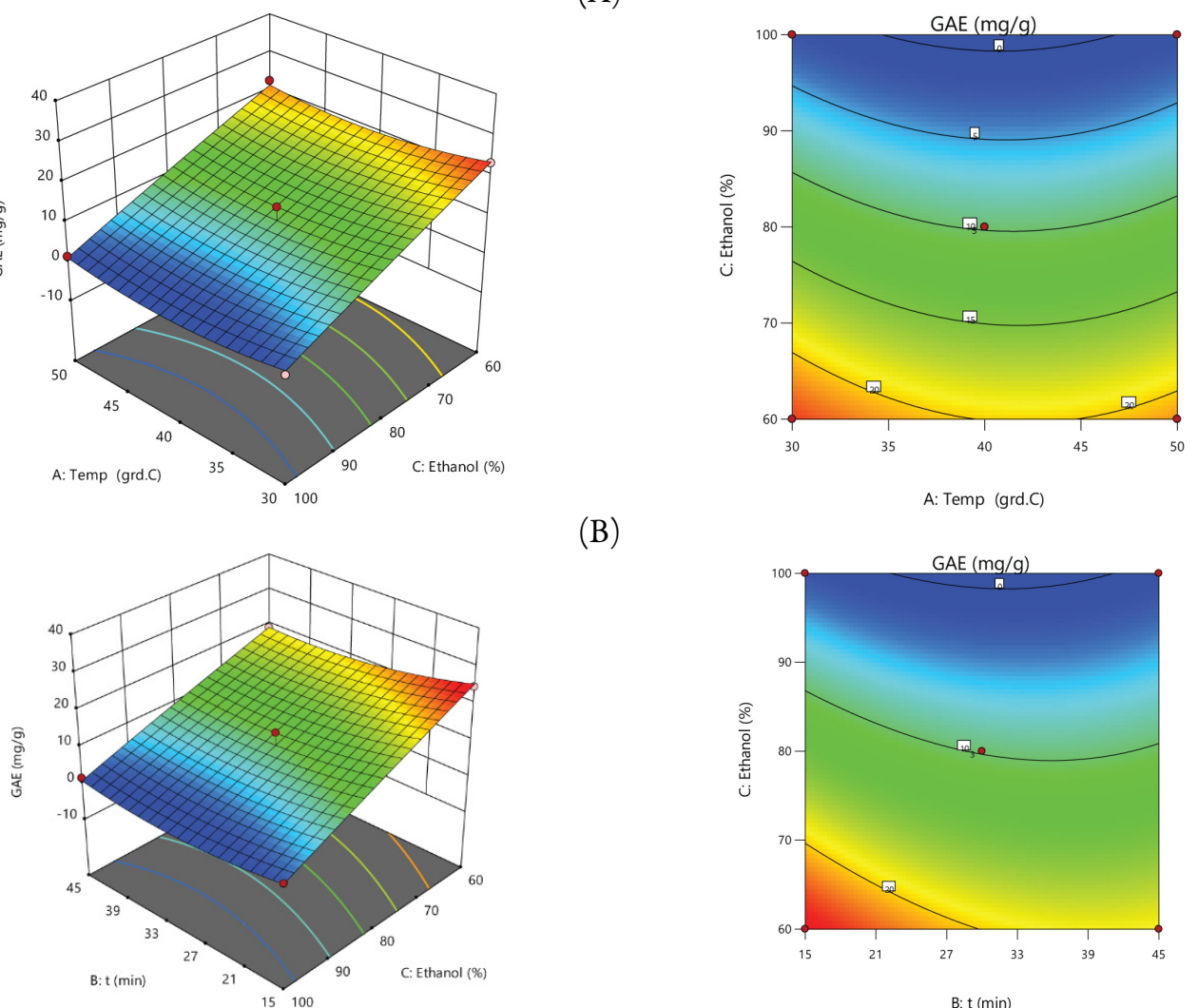

(B)

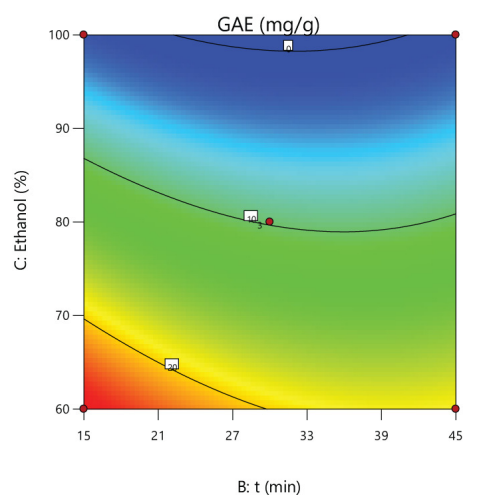

(C)

Figure 7. Response surface and contour plot that share the combined effect of temperature (A), time extraction (B) and $\mathrm{EtOH}$ concentration (C) on the TPC content 
Enache I-M et al. (2021). Not Bot Horti Agrobo 49(2):12307
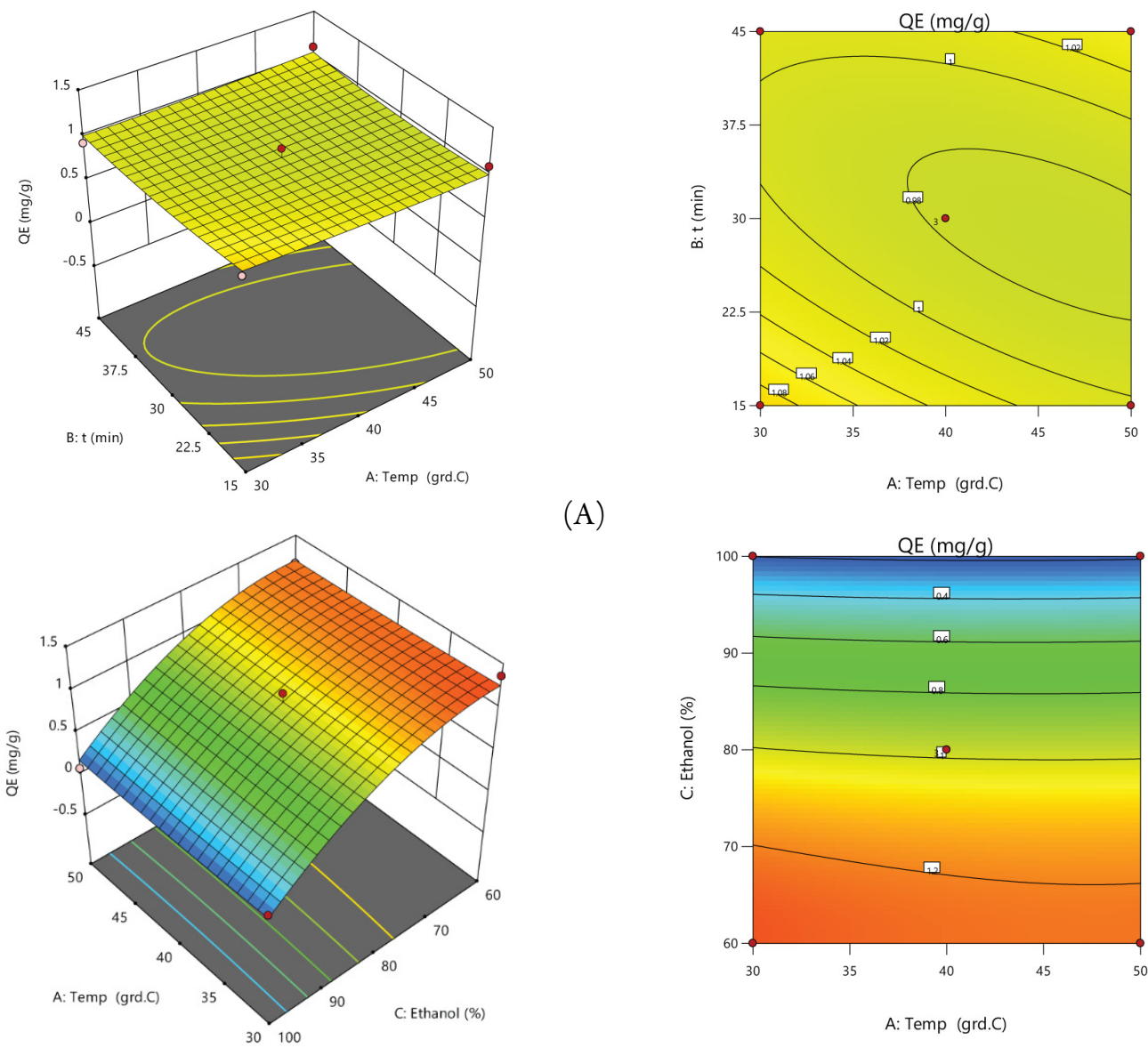

(A)
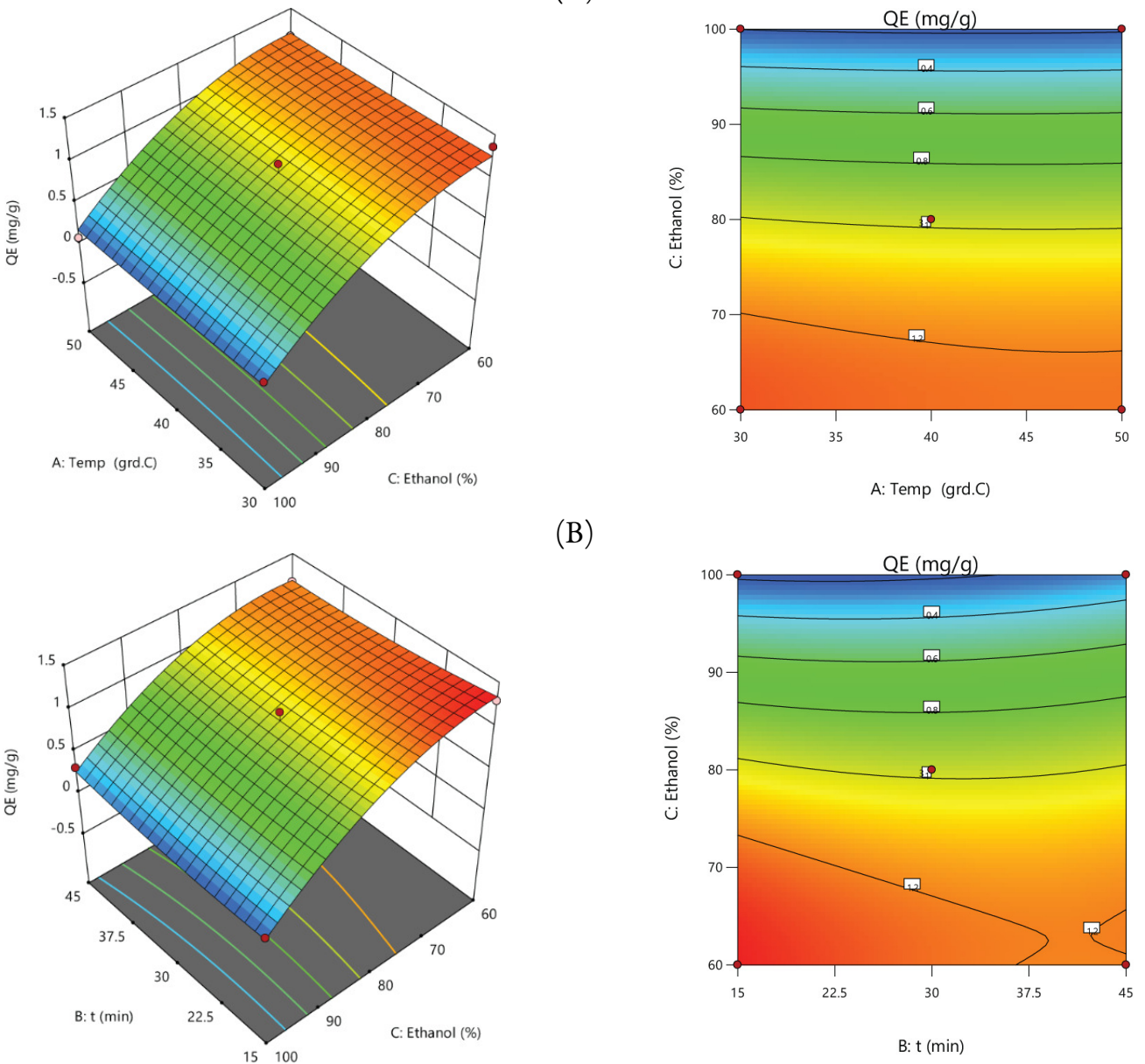

(C)

Figure 8. Response surface and contour plot that share the combined effect of temperature (A), time extraction (B) and EtOH concentration (C) on the TFC content 

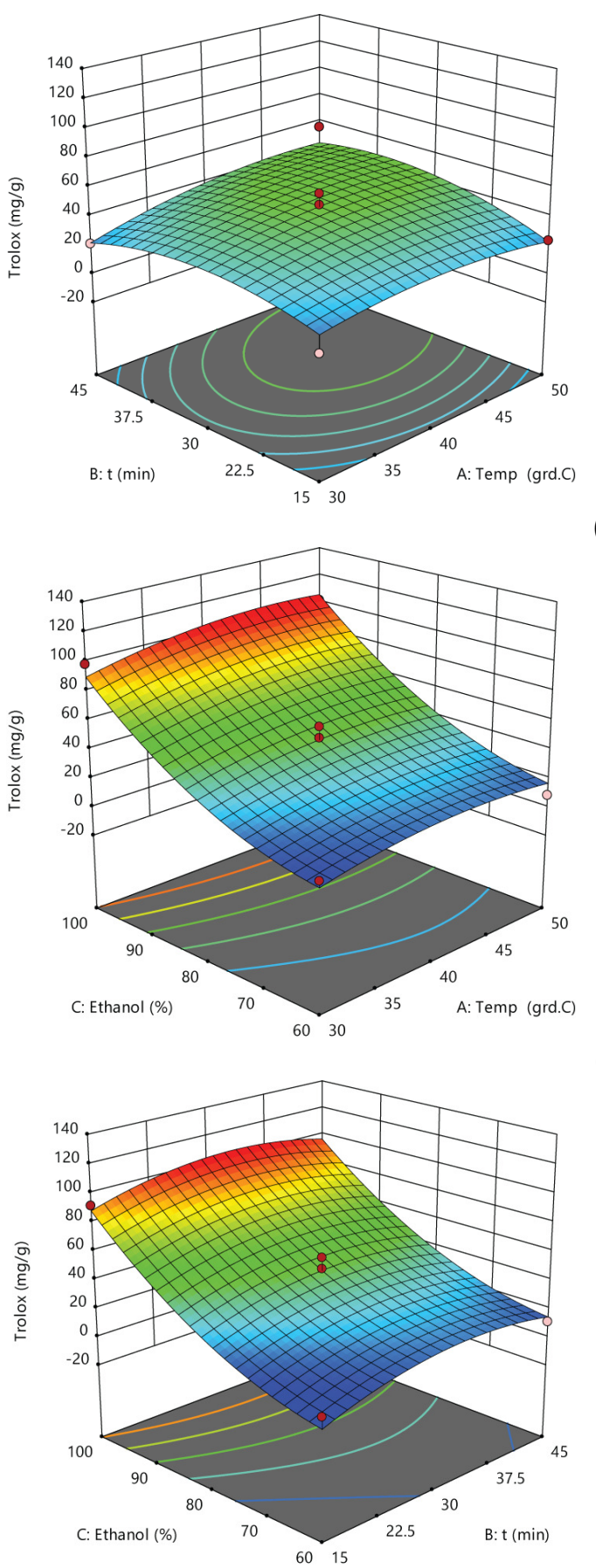

(B)

(A)
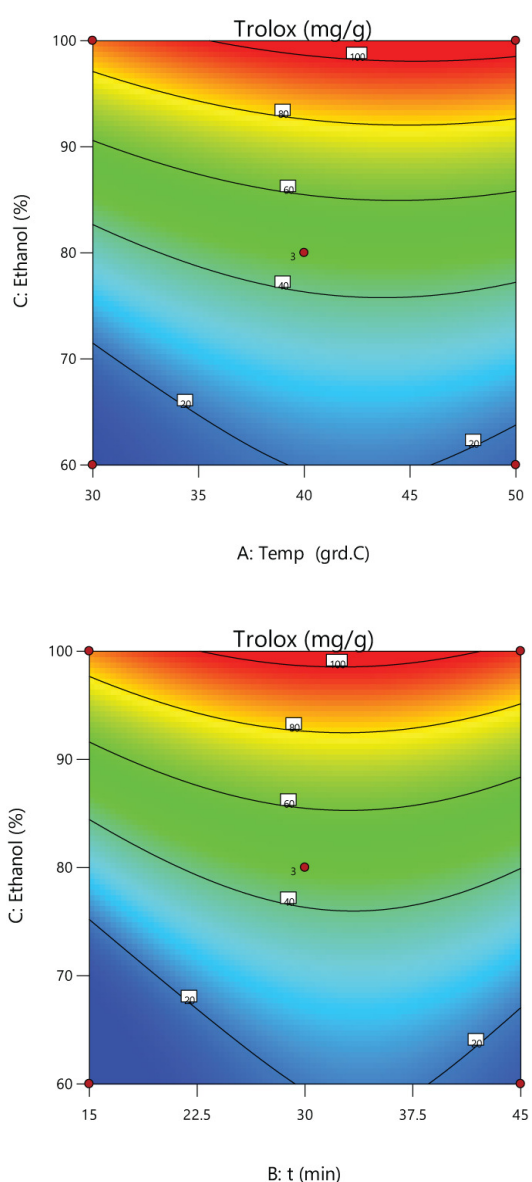

(C)

Figure 9. Response surface and contour plot that share the combined effect of temperature (A), time extraction (B.) and EtOH concentration (C) on TAA

Using the optimum concentration of $100 \% \mathrm{EtOH}$, the optimum extraction time for the temperature range of $30-50{ }^{\circ} \mathrm{C}$ is $15-45$ minutes. A maximum concentration was reached after 30 minutes of extraction (Figure 9C).

The experimental values (observed values) and those predicted for the TPC are found in the immediate vicinity of the correlation line, which shows that the model predicted the experimental data very well, fact also 
proven by the coefficient of determination value $\mathrm{R}^{2}=0.86$ (quadratic model). This shows that $86 \%$ of the experimental data are approximated by the model. The remaining $14 \%$ represents the residual values of the model (Figure 10A). The experimental values (observed values) and those predicted for the TFC are found in the immediate vicinity of the correlation line, which shows that the model predicts the experimental data very well, fact also proven by the coefficient of determination value $\mathrm{R}^{2}=0.97$ (quadratic model). This indicates that $97 \%$ of the experimental data were approximated by the model; the remaining $3 \%$ represents the residual values of the model (Figure 10B). The experimental values (observed values) and those predicted for the TAA are found in the immediate vicinity of the correlation line, which confirms that the model predicts the experimental data very well, fact proven by the coefficient of determination value $\mathrm{R}^{2}=0.95$ (quadratic model). This proves that $95 \%$ of the experimental data were approximated by the model; the remaining $5 \%$ being the residual values of the model (Figure 10C).

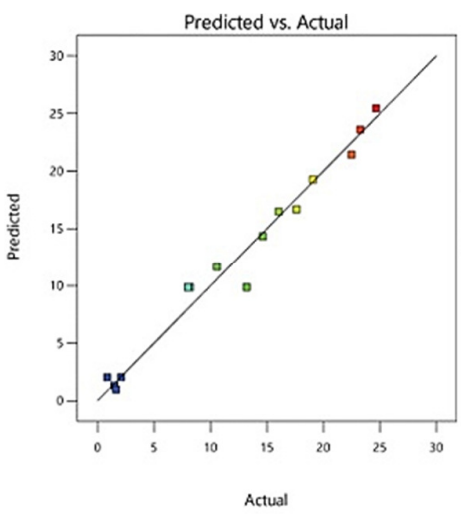

(A)

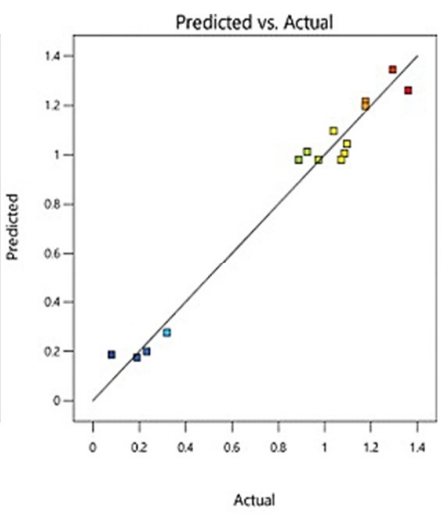

(B)

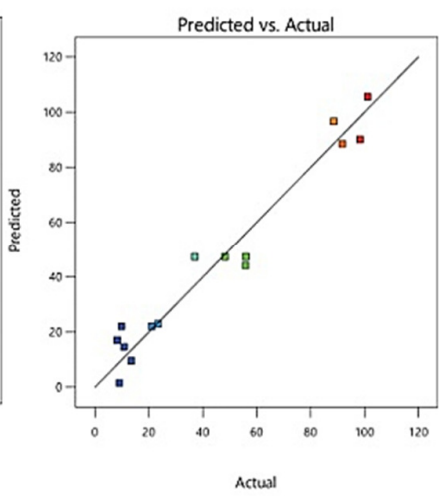

(C)

Figure 10. Actual versus predicted values acquired through a second-order polynomial model to analyse the TPC (A), the TFC (B) and the TAA (C)

The study of the extraction parameters effects values on the concentration of the TPC revealed that the $\mathrm{EtOH}$ concentration had a high degree of influence, being able to vary between $60-80 \%$ when the GAE concentration was between $10-20 \mathrm{mg} / \mathrm{g}$ raw material. The time and temperature parameters did not significantly influence the extraction process, the critical values being represented by the temperature of $40{ }^{\circ} \mathrm{C}$ and the extraction time of $30 \mathrm{~min}$ when a decrease of the TPC was observed (Figure 11A). The study of the effects of the extraction parameters on the concentration of the TFC showed that the $\mathrm{EtOH}$ concentration was again very important, being able to vary between $60-80 \%$ when the QE concentration is between $1-1.4 \mathrm{mg}$ /g raw material. Moreover, the time and temperature parameters did not significantly influence the extraction process (Figure 11B). The study of the effects of the extraction parameters on the concentration of the TPC showed that $\mathrm{EtOH}$ concentration could vary between $80-100 \%$ when the concentration of phenolic compounds is between $40-100 \mathrm{mg} / \mathrm{g}$ raw material. The time and temperature parameters did not significantly influence the extraction process critical values that were represented by the temperature of $30^{\circ} \mathrm{C}$ and the extraction time of $15 \mathrm{~min}$ when a decrease of the TPC was detected (Figure 11C).

The central-face cube model for the Box-Behnken central composition revealed the highest concentration value of the TPC (28.43 mg GAE/g raw material) and TFC ( $1.41 \mathrm{mg}$ QE/g raw material) at a $60 \%$ ethanol concentration, $30^{\circ} \mathrm{C}$ extraction temperature and a maximum extraction time of $15 \mathrm{~min}$ (Figure 12a and Figure 12b). The cube model with the centred faces for the Box-Behnken central composition revealed the highest value of the concentration of the TAA (102.49 mg TE/g raw material) at an 100\% ethanol concentration, $50^{\circ} \mathrm{C}$ extraction temperature and maximum $45 \mathrm{~min}$ extraction time (Figure 12c). From the analysis of the experimental values compared to those offered by the model, it was observed that the time variables (for the TFC and the TAA) and temperature (for the TPC) are limiting factors. 


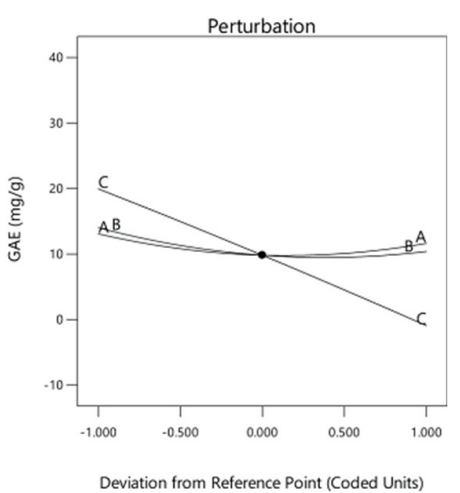

(A)

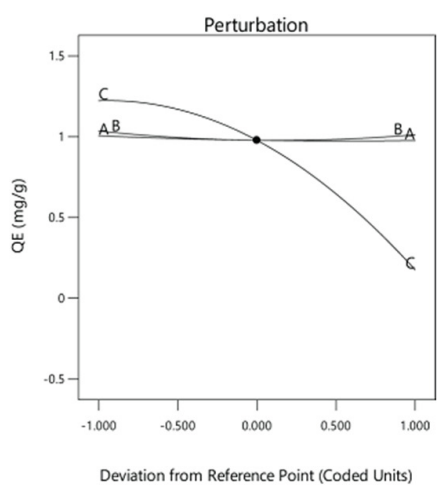

(B)

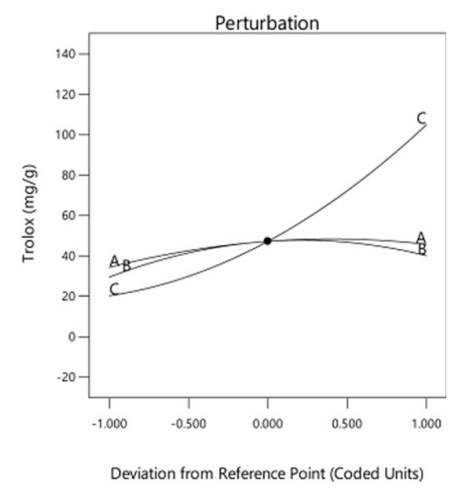

(C)

Figure 11. Perturbation graphics acquired using a second-order polynomial model for the TPC (A), the TFC (B) and the TAA (C)

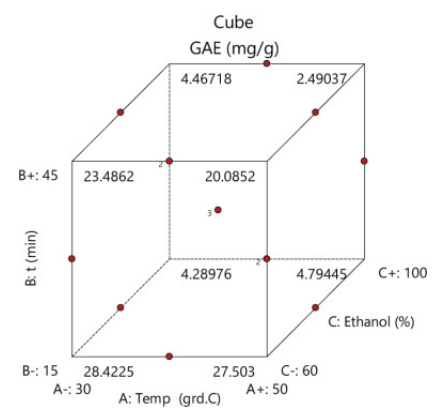

(A)

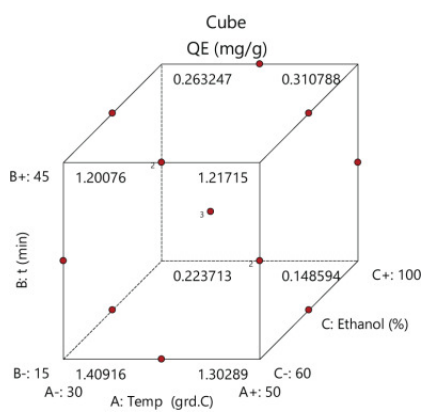

(B)

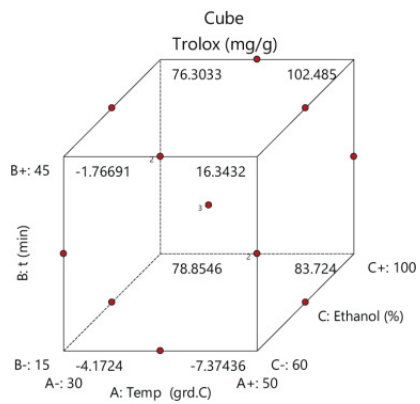

(C)

Figure 12. Perturbation graphics acquired using a second-order polynomial model for a the TPC (A), the TFC (B) and the TAA (C)

\section{Conclusions}

In our GIS technique research, the validation of the model involved identifying its success rate based on a direct comparison between the predicted and the determined results. The validation of the model through the proposed method displayed a validation rate of $83.5 \%$ was obtained which highlights the correctness of the primary databases preparation, the methodology proposed as the basis of the spatial analysis and provides the means for the implementation within the analysed territory, the main purpose being decision-making when planting species adapted to the current climatic and environmental conditions.

The Response Surface Methodology was employed to study the extraction parameters effect: temperature $\left(30-50{ }^{\circ} \mathrm{C}\right)$, time $(15-45 \mathrm{~min}$.) and $\mathrm{EtOH}$ concentration $(60-80 \%)$ on the BACs from the cornelian cherry fruits extract. As such, the flavonoids and polyphenols concentrations and the antioxidant activity values were determined. The highest values for the TPC and the TFC were obtained at $60 \% \mathrm{EtOH}$ concentration and different values for the temperature and time. The most relevant variable was the EtOH concentration, the obtained results suggesting that the experimental data were well approximated by the central-face cube model ( $86 \%$ for the TPC, $97 \%$ for the TFC and $95 \%$ the TAA).

On the territory of Romania, the beneficiaries of our study can be the territorial administrative units or NGOs regarding reforestation deficient areas in C. mas. In addition, the growth of the area of this plant may attract the interest of the food industry in diversifying different ingredients made from this variety. The results of the study create also the premises of further research for obtaining a functional food based on C. mas fruits' extract. 


\section{Authors' Contributions}

Conceptualization EIM, LM; Data curation LM, CV; Formal analysis EIM, SR, GC; Funding acquisition LM; Investigation EIM, SR, GC; Methodology SR, GC; Project administration LM, CV; Resources LM; Software SR, GC; Supervision LM, CV; Validation LM, CV; Visualization LM; Writing original draft EIM, LM; Writing - review and editing LM, CV. All authors read and approved the final manuscript.

\section{Acknowledgements}

The authors are grateful to the Integrated Center for Research, Expertise and Technological Transfer in Food Industry for providing technical support (http://www.bioaliment.ugal.ro/index_en.html). Dr. Eliza Ţupu from Museal Complex 'Rasvan Angheluta' Galati is acknowledged for plant material identification.

This work was supported by mobility grants of the Romanian Ministry of Research and Innovation, CNCS - UEFISCDI, project numbers PN-III-P1-1.1-MC-2019-1905 and PN-III-P1-1.1-MC-2019-1908, within PNCDI III.

\section{Conflict of Interests}

The authors declare that there are no conflicts of interest related to this article.

\section{References}

Acharya P, Biradar C, Louhaichi M, Ghosh S, Hassan S, Moyo H, Sarker A (2019). Finding a suitable niche for cultivating cactus pear (Opuntia ficus-indica) as an Integrated crop in resilient dryland agroecosystems of India. Sustainability 11:5897. https://doi.org/10.3390/su11215897

Altemimi A, Lakhssassi N, Baharlouei A, Watson DG, Lightfoot DA (2017). Phytochemicals: Extraction, isolation, and identification of bioactive compounds from plant extracts. Plants 6(4):23. https://doi.org/10.3390/plants6040042

Asgary S, Kelishadi R, Rafieian-Kopaei M, Najafi S, Najafi M, Sahebkar A (2013). Investigation of the lipid-modifying and anti-inflammatory effects of Cornus mas L. supplementation on dyslipidemic children and adolescents. Pediatric Cardiology 34(7):1729-1735. https://doi.org/10.1007/s00246-013-0693-5

Beck P, Caudullo G, Mauri A, De Rigo D, Durrant T, San-Miguel-Ayanz J (2020). Tree species distribution data and maps for Europe. EUR 30148 EN, Publications Office of the European Union, Luxembourg.

Bhandari S, Jhadav ST, Kumar S (2013). Land capability classification and crop suitability assessment in a watershed using RS andGIS - a case study of watershed in Dehradun, Uttarakhand. SSARSC International Journal of Geo Science and Geo Informatic 1(1):1-15.

Capanoglu E, Boyacioglu D, De Vos RCH, Hall RD, Beekwilder J (2011). Procyanidins in fruit from Sour cherry (Prunus cerasus) differ strongly in chain length from those in Laurel cherry (Prunus lauracerasus) and Cornelian cherry (Cornus mas). Journal of Berry Research 1(3):137-146. https://doi.org/10.3233/BR-2011-015

Cornescu FC, Cosmulescu SN. (2017). Morphological and biochemical characteristics of fruits of different Cornelian cherry (Cornus mas L.) genotypes from spontaneous flora. Notulae Scientia Biologicae 9(4):577-581. https://doi.org/10.15835/nsb9410161

Dhanani T, Singh R, Shah S, Kumari P, Kumar S (2015). Comparison of green extraction methods with conventional extraction method for extract yield, L-DOPA concentration and antioxidant activity of Mucuna pruriens seed. Green Chemistry Letters and Reviews 8(2):43-48. https://doi.org/10.1080/17518253.2015.1075070 
Dinda B, Kyriakopoulos AM, Dinda S, Zoumpourlis V, Thomaidis NS, Velegraki A, ... Dinda M (2016). Review Cornus mas L. (cornelian cherry), an important European and Asian traditional food and medicine: Ethnomedicine, phytochemistry and pharmacology for its commercial utilization in drug industry. Journal of Ethnopharmacology 193:670-690. https://doi.org/10.1016/j.jep.2016.09.042

Doniță N, Popescu A, Paucă-Comănescu M, Mihăilescu S, Biriș IA (2005). Habitatele din România. Editura Tehnicã Silvicã.

Dumitrașcu L, Enachi E, Stănciuc N, Aprodu I (2019). Optimization of ultrasound assisted extraction of phenolic compounds from cornelian cherry fruits using response surface methodology. CyTA - Journal of Food 17(1):814-823. https://doi.org/10.1080/19476337.2019.1659418

Ercişli S (2004). Cornelian cherry germplasm resources of Turkey. Journal of Fruit and Ornamental Plant Research 12:8792.

Güleryüz M, Bolat I, Pirlak L (1998). Selection of table cornelian cherry (Cornus mas L.) types in Coruh valley. Turkish Journal of Agriculture and Forestry 22:357-364. https://doi.org/10.3906/tar-96062

Islam MM, Ahamed T, Noguchi R (2018). Land suitability and insurance premiums: A GIS-based multicriteria analysis approach for sustainable rice production. Sustainability 10:1759. https://doi.org/10.3390/su10061759

Kim SS, Lee CK, Kang HM, Choi SI, Jeon SH, Kim H (2021) Land suitability evaluation for wild-simulated ginseng cultivation in South Korea. Land 10:94. https://doi.org/10.3390/land10020094

Matei I, Pacurar I, Rosca S, Bilasco S, Sestras P, Rusu T, ... Tăut FD (2020). Land use favourability assessment based on soil characteristics and anthropic pollution. Case study Somesul Mic Valley corridor, Romania. Agronomy 10(9):1245. https://doi.org/10.3390/agronomy10091245

Nipornram S, Tochampa W, Rattanatraiwong P, Singanusong R (2018). Optimization of low power ultrasound-assisted extraction of phenolic compounds from mandarin (Citrus reticulata Blanco cv. Sainampueng) peel. Food Chemistry 241:338-345. https://doi.org/10.1016/j.foodchem.2017.08.114

Nizioł-Łukaszewska Z, Wasilewski T, Bujak T, Gaweł-Bęben K, Osika P, Czerwonka D (2018). Cornus mas L. extract as a multifunctional material for manufacturing cosmetic emulsions. Chinese Journal of Natural Medicines 16(4):284-292. https://doi.org/10.1016/s1875-5364(18)30058-X

Oancea AM, Aprodu I, Ghinea IO, Barbu V, Ioniță E, Bahrim G, ... Stănciuc N (2017). A bottom-up approach for encapsulation of sour cherries anthocyanins by using $\beta$-lactoglobulin as matrices. Journal of Food Engineering 210:83-90. https://doi.org/10.1016/j.jfoodeng.2017.04.033

Roșca S, Bilașco Ș, Păcurar I, Colniță D, Fodorean I, Vescan I, ... Păcurar H (2017). Quantitative evaluation of forest favourability using GIS database in a hill area in the Transylvania Depression, Romania. Geomatics, Natural Hazards and Risk 8(2):1914-1934. https://doi.org/10.1080/19475705.2017.1401012

Rosca S, Simonca V, Bilasco Ș, Vescan I, Fodorean I, Petrea D (2019). Assessment of favourability and spatio-temporal dynamics of Pinus mugo in the Romanian Carpathians using GIS technology and Landsat images. Sustainability 11(13):30. https://doi.org/10.3390/su11133678

Schiop ST, Al Hassan M, Sestras AF, Boscaiu M, Sestras RE, Vicente O (2017). Biochemical responses to drought, at the seedling stage, of several Romanian Carpathian populations of Norway spruce (Picea abies L. Karst). TreesStructure and Function 31(5):1479-1490. https://doi.org/10.1007/s00468-017-1563-1

Seidl R, Thom D, Kautz M, Martin-Benito D, Peltoniemi M, Vacchiano G, ... Reyer CP (2017). Forest disturbances under climate change. Nature Climate Change 7(6):395-402. https://doi.org/10.1038/nclimate3303

Sochor J, Jurikova T, Ercisli S, Mlcek J, Baron M, Balla S, ... Necas T (2014). Characterization of cornelian cherry (Cornus mas L.) genotypes - genetic resources for food production in Czech Republic. Genetika 46(3):915-924. https://doi.org/10.2298/GENSR1403915S

Szumny D, Sozański T, Kucharska AZ, Dziewiszek W, Piórecki N, Magdalan J, ... Szumny A (2015). Application of cornelian cherry iridoid-polyphenolic fraction and loganic acid to reduce intraocular pressure. Evidence-Based Complementary and Alternative Medicine 939402:8. https://doi.org/10.1155/2015/939402

Tatke P, Rajan M (2014). Comparison of conventional and novel extraction techniques for the extraction of scopoletin from Convolvulus pluricaulis. Indian Journal of Pharmaceutical Education and Research 48(1):27-31. https://doi.org/10.5530/ijper.48.1.5

Todea Morar IM, Rensen S, Vilanova S, Boscaiu M, Holonec L, Sestras AF ... Plazas M (2020). Genetic relationships and reproductive traits of Romanian populations of silver fir (Abies alba): Implications for the sustainable management of local populations. Sustainability 12(10):4199. https://doi.org/10.3390/su 12104199 
Turturică M, Stănciuc N, Bahrim G, Râpeanu G (2016). Effect of thermal treatment on phenolic compounds from plum (Prunus domestica) extracts - A kinetic study. Journal of Food Engineering 171:200-207. https://doi.org/10.1016/j.jfoodeng.2015.10.024

Vasile AM, Milea ȘA, Enachi E, Barbu V, Circiumaru A, Bahrim G, ... Stanciuc N (2020). Functional enhancement of bioactives from black beans and lactic acid bacteria into an innovative food ingredient by Comicroencapsulation. Food and Bioprocess Technology 13(2):978-987. https://doi.org/10.1007/s11947-02002451-8

Xu E, Zhang H, Yang Y, Zhang Y (2014). Integrating a spatially explicit trade-off analysis for sustainable land use optimal allocation. Sustainability 6:8909-8930. https://doi.org/10.3390/su6128909

Zeković Z, Vidović S, Vladić J, Radosavljević R, Cvejin A, Elgndi MA, Pavlić B (2014). Optimization of subcritical water extraction of antioxidants from Coriandrum sativum seeds by response surface methodology. Journal of Supercritical Fluids 95:560-566. https://doi.org/10.1016/j.supflu.2014.09.004

OPEN ACCESS

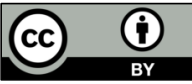

The journal offers free, immediate, and unrestricted access to peer-reviewed research and scholarly work. Users are allowed to read, download, copy, distribute, print, search, or link to the full texts of the articles, or use them for any other lawful purpose, without asking prior permission from the publisher or the author.

License - Articles published in Notulae Botanicae Horti Agrobotanici Cluj-Napoca are Open-Access, distributed under the terms and conditions of the Creative Commons Attribution (CC BY 4.0) License.

(C) Articles by the authors; UASVM, Cluj-Napoca, Romania. The journal allows the author(s) to hold the copyright/to retain publishing rights without restriction. 